\title{
Thematic course: Kinetics and mechanism of acyl transfer reactions. Part 15. \\ Quantumchemicalsimulation of mechanisms of reactions of $N$-ethylaniline sulfonation
}

\author{
(C) Ludmila B. Kochetova and Tatiana P. Kustova** \\ Department of Organic and Physical Chemistry.Ivanovo State University. \\ Ermak St., 39. Ivanovo, 153025. Russia.Phone: +7 (84932)37-37-03.E-mail: kustova_t@mail.ru
}

\begin{abstract}
*Supervising author; ${ }^{+}$Corresponding author
Keywords: quantum chemical simulation, reaction mechanism, sulfonylation, $N$-ethylaniline, benzenesulfonyl chloride.
\end{abstract}

\begin{abstract}
The RHF/6-31G(d) quantum chemical simulation of the mechanism of the interaction of the secondary fatty aromatic amine $N$-ethylaniline with benzenesulfonyl chloride under conditions of non-specific water solvation, using the continuum model of the solvent, as well as of sulfonylation reactions of $N$-ethylaniline solvation complexes containing one water molecule, modeled specific solvation of $N$-ethylaniline with water, and one molecule of water and one of dioxane, which simulate the solvation of the amine with aqueous dioxane. Three-dimensional potential energy surface of these processes is calculated. It is shown that in the case of a reaction proceeding under conditions of non-specific solvation of reagents, the route with axial attack of the $N$-ethylaniline molecule to the sulfonyl reaction center is realized, in the two other cases the reactions proceed along a single route, starting as an axial attack of the nucleophile, which goes further with decreasing of the attack angle as reagent molecules approach each other. It was established that all the simulated reactions proceed in accordance with bimolecular coordinated mechanism of nucleophilic substitution $\mathrm{S}_{\mathrm{N}} 2$, which implies the formation of a single transition state in the reaction path. It was found that geometrical configuration of the reaction center in the transition state of $N$-ethylaniline reaction with benzenesulfonyl chloride under non-specific solvation by water is close to trigonal-bipyramidal, which is determined by the axial direction of the nucleophilic attack, in the two other cases it is medium between the trigonal-bipyramidal and tetragonal-pyramidal, which is associated with the change in the angle of $\mathrm{N}$ ethylaniline attack as the reactant molecules approach each other. In a reaction involving $N$-ethylaniline monohydrate, a water molecule forms a 6-membered cyclic structure with reagent molecules in the transition state, in which the transfer of a proton from $N$-ethylaniline amino group to a hydrogen chloride molecule occurs via a relay mechanism involving the water molecule. The activation energy values of the studied processes were calculated; it is shown that both specific and universal solvation significantly lower the energy barrier of the reaction compared to the reaction occurring in gas phase, which is consistent with the data obtained earlier for related processes.
\end{abstract}

\section{References}

[1] I.S. Antipin, M.A. Kazymova, M.A. Kuznetsov, A.V. Vasil'ev, M.A. Ishchenko, A.A. Kiryushkin, L.M. Kuznetsova, S.V. Makarenko, V.A. Ostrovskii, M.L. Petrov, O.V. Solod, Yu.G. Trishin, I.P. Yakovlev, V.G. Nenaidenko, E.K. Beloglazkina, I.P. Beletskaya, Yu.A. Ustynyuk, P.A. Solov'ev, I.V. Ivanov, E.V. Malina, N.V. Sivova, V.V. Negrebetskii, Yu.I. Baukov, N.A. Pozharskaya, V.F. Traven', A.E. Shchekotikhin, A.V. Varlamov, T.N. Borisova, Yu.A. Lesina, E.A. Krasnokutskaya, S.I. Rogozhnikov, S.N. Shurov, T.P. Kustova, M.V. Klyuev, O.G. Khelevina, P.A. Stuzhin, A.Yu. Fedorov, A.V. Gushchin, V.A. Dodonov, A.V. Kolobov, V.V. Plakhtinskii, V.Yu. Orlov, A.P. Kriven'ko, O.V. Fedotova, N.V. Pchelintseva, V.N. Charushin, O.N. Chupakhin, Yu.N. Klimochkin, A.Yu. Klimochkina, V.N. Kuryatnikov, Yu.A. Malinovskaya, A.S. Levina, O.E. Zhuravlev, L.I. Voronchikhina, A.S. Fisyuk, A.V. Aksenov, N.A. Aksenov, I.V. Aksenova. Organic chemistry. History and mutual relations of universities of Russia. Russian journal of organic chemistry. 2017. Vol.53. No.9. P.1-165. DOI: $10.1134 / \mathrm{S} 1070428017090019$

[2] T.P. Kustova, L.B. Kochetova, and N.V. Kalinina. Reactivity of $\alpha$-alanine in arensulfonylation in aqueous-organic media: kinetic experiment and reaction root simulation. Butlerov Communications. 2011. Vol.27. No.13. P.1-12. ROI: jbc-02/11-27-13-1 
[3] N.R. Sokolova, E.V. Nikitina, L.B. Kochetova, N.V. Kalinina, and T.P. Kustova. Kinetics and mechanism of acyl transfer reactions. Part 2.Kinetics of heterocyclic amines arensulfonylation in aqueous 1,4-dioxane. Butlerov Communications. 2012. Vol.29. No.1. P.7-14. ROI: jbc-02/12-29-1-7

[4] L.B. Kochetova, N.V. Kalinina, L.V. Kuritsyn, E.V. Nikitina and T.P. Kustova. The kinetics and mechanism of the acyl transfer. Part 3. Glycine and ammonia reactivity in acyl transfer reactions. Butlerov Communications. 2012. Vol.30. No.6. P.81-88. ROI: jbc-02/12-30-6-81

[5] L.B. Kochetova, M.G. Paikova, N.V. Kalinina, and T.P. Kustova. Kinetics and mechanism of acyl transfer reactions. Part IV.Quantum chemical simulation of the mechanism of benzoylchloride and benzenesulphonyl chloride interactions with amino compounds of different classes. Butlerov Communications. 2013. Vol.35. No.9. P.1-8. ROI: jbc-02/13-35-9-1

[6] L.B. Kochetova, N.V. Kalinina, T.P. Kustova, and L.V. Kuritsyn. Kinetics and mechanism of acyl transfer reactions. Part 5.Dipeptides and amino acids reactivity in sulfamide bond formation processes. Butlerov Communications. 2013. Vol.36. No.12. P.1-7. ROI: jbc-02/13-36-12-1

[7] L.B. Kochetova, N.V. Kalinina, T.P. Kustova, and L.V. Kuritsyn. Kinetics and mechanism of acyl transfer reactions. Part 6. Quantum chemical interpretation of dipeptides and aminoacids reactivity in processes of acids amides and sulfamides formation. Butlerov Communications. 2013. Vol.36. No.12. P.97-104. ROI: jbc-02/13-36-12-97

[8] L.V. Kuritsyn, L.B. Kochetova, N.V. Kalinina, and T.P. Kustova. Kinetics and mechanism of acyl transfer reactions. Part 7. Influence of $\mathrm{pH}$ medium on the reactivity of amines in $\mathrm{N}$-acylation. Butlerov Communications. 2014. Vol.37. No.1. P.33-38. ROI: jbc-02/14-37-1-33

[9] L.B. Kochetova, N.V. Kalinina, L.V. Kuritsyn, and T.P. Kustova. Kinetics and mechanism of acyl transfer reactions. Part 9. Influence of ester structures on kinetics of piperidine and morfoline $N$ acylation in aqueous-organic solvents. Butlerov Communications. 2014. Vol.40. No.11. P.59-66. ROI: jbc-02/14-40-11-59

[10] L.B. Kochetova, N.V. Kalinina, Yu.E. Grabchil'ova, K.A. Simonova, and T.P. Kustova. Kinetics and mechanism of acyl transfer reactions. Part 10. Reactivity of dipeptides and esters of carboxylic acids at their interaction in aqueous dioxane solutions. Butlerov Communications. 2015. Vol.43. No.7. P.1-11. DOI: $10.37952 /$ ROI-jbc-01/15-43-7-1

[11] L.B. Kochetova, N.V. Kalinina, D.S. Soloviyova, O.Yu. Dicina, L.V. Kuritsyn, and T.P. Kustova. Kinetics and mechanism of acyl transfer reactions. Part 11.L-Lysine and $L$-ornitine reactivity in reactions with 4-nitrophenyl acetate and picryl benzoate in aqueous 1,4-dioxane solutions. Butlerov Communications. 2016. Vol.45. No.1. P.145-151. DOI: 10.37952/ROI-jbc-01/16-45-1-145

[12] L.B. Kochetova, T.P. Kustova, L.V. Kuritsyn, and O.Y. Dicyna. Kinetics and mechanism of acyl transfer reactions. Part 12. Reactivity of aryl amines in amides formation. Butlerov Communications. 2016. Vol.47. No.9. P.95-105. DOI: $10.37952 /$ ROI-jbc-01/16-47-9-95

[13] L.B. Kochetova, T.P. Kustova, D.E. Troitskaya, and Yu.M. Romanova. Kinetics and mechanism of acyl transfer reactions. Part 13. Quantum chemical simulation of mechanisms of the reactions of secondary fatty aromatic amines arensulfonation. Butlerov Communications. 2017. Vol.51. No.9. P.45-56. DOI: 10.37952/ROI-jbc-01/17-51-9-45

[14] L.B. Kochetova, and T.P. Kustova. Kinetics and mechanism of acyl transfer reactions. Part14. Aminolysis of esters: kinetic experiment and computer simulationof the mechanism. Butlerov Communications. 2018. Vol.53. No.3. P.33-56. DOI: 10.37952/ROI-jbc-01/18-53-3-33

[15] N.N. Vorozhtsov. Basics of the synthesis of intermediates and dyes. 4-th ed. Moscow: Goskhimizdat. 1955. 839p. (russian)

[16] K.U. Buller. Heat and heat resistant polymers. Moscow: Khimiya.1984. 1056p. (russian)

[17] M.D. Mashkovsky. Medicines. Moscow: Novaya Volna. 2006. 1206p. (russian)

[18] Merck Index. Ed. byBudavari S. 11thed. N.Y.: Merck\&Co., Rahway. 1989. P.1400-1416.

[19] Kinetics of acyl transfer reaction. Kuristyn L.V. [and etc.]; ed. by L.V. Kuristyn. Ivanovo: Ivan. gos. univ. 2006. 260p. (russian)

[20] A.A. Granovsky. Firefly version 7.1.G. wwwhttp://classic.chem.msu.su/gran/firefly/index.html

[21] L.B. Kochetova, T.P. Kustova, L.V. Kuristyn, A.A. Katushkin. Arenesulfonylation of N-alkylanilines: reaction kinetics and mechanism. Russian chemical bulletin. 2017. Vol.66. No.6. P.999-1006. DOI: 10.1007/s11172-017-1846-0

[22] A.S. Dneprovskiy, T.I. Temnikova. Theoretical Foundations of Organic Chemistry. 2 ed. Leningrad: Khimia. 1991. 560p. (russian)

[23] L.B. Kochetova, T.P. Kustova, N.V. Kalinina, N.R. Ishkulova, V.V. Lutsuk. Quantum-chemical modeling of the mechanism of interaction of arsulfonyl chlorides with $\alpha$-amino acids. Theoretical and Experimental Chemistry. 2011. Vol.47. No.1. P.56-60. (russian) 